\title{
Sirolimus and nefazodone interaction in a renal transplant patient
}

\author{
Laura S. Michalski* \\ Dimple Bhuva** \\ Anita Pakrasi*** \\ David R. Holt ${ }^{\star \star \star *}$ \\ Susan H. Hou ${ }^{\star \star \star \star \star}$
}

* U.S. Medical Affairs-Specialty Care-

Transplantation, Pfizer Inc., West New York, NJ

** Pharmacy Department, Walgreens, Chicago, IL; Pharmacy Department, Loyola University Medical Center, Maywood, IL

*** Department of Kidney Transplant, Loyola University Medical Center, Maywood, IL

**** Department of Surgery, Loyola University Medical Center, Maywood, IL

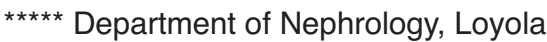
University Medical Center, Maywood, IL

USA

\footnotetext{
ABSTRACT - Background and Objectives: Our case demonstrates the first report of an interaction with sirolimus and nefazodone in a stable renal transplant patient. Nefazodone can inhibit cytochrome P450 3A4 and may result in elevated concentrations of sirolimus since sirolimus is metabolized by cytochrome P450 3A4.

Methods: A 44-year-old patient was taking nefazodone pre-transplant and post-transplant. When nefazodone was discontinued the sirolimus level was undetectable.

Results: This drug interaction was not suspected because the patient was on nefazodone pre-transplant.

Conclusions: It is very important to monitor the sirolimus trough level when nefazodone is initiated, discontinued, or the dose is adjusted to prevent sirolimus subtherapeutic or supratherapeutic trough levels.
} 


\section{Introduction}

Nefazodone is an antidepressant that is both metabolized and inhibits the cytochrome P450 3A4 enzyme system ${ }^{1,2}$. Common adverse effects are sedation and orthostatic hypotension, which may be of benefit in a patient with insomnia and/or hyperten$\operatorname{sion}^{1,2}$. Sirolimus is an immunosuppressant used to prevent acute rejection in organ transplant patients. Sirolimus is a substrate for cytochrome P450 3A4 $4^{3}$; therefore, drugs that inhibit cytochrome P450 3A4, such as nefazodone, may result in elevated sirolimus levels. Our case report demonstrates the first potential interaction with sirolimus and nefazodone in a stable renal transplant patient.

\section{Case report}

A 44-year-old patient received a renal transplant in December 2000. Her immunosuppression consisted of cyclosporine, mycophenolate mofetil, and prednisone. The patient was on nefazodone $150 \mathrm{mg}$ twice daily pre-transplant and the dose was later increased to $300 \mathrm{mg}$ twice daily. In January 2003 , the patient was switched from cyclosporine to sirolimus, target sirolimus trough level was 5-8 ng/mL. In September 2003, her sirolimus trough level was therapeutic at $6.5 \mathrm{ng} / \mathrm{mL}$ maintained on $1 \mathrm{mg}$ every other day. In October 2003, the sirolimus trough level decreased to $\leq 1.0 \mathrm{ng} / \mathrm{mL}$. The patient was immediately contacted and she stated her nefazodone was discontinued. The sirolimus dose was immediately increased to $1 \mathrm{mg}$ daily, with a subsequent sirolimus trough level that was subtherapeutic at 2.7 $\mathrm{ng} / \mathrm{mL}$ one week later. The sirolimus dose was then further increased to $2 \mathrm{mg}$ daily and the resulting sirolimus trough level was later therapeutic at $5.6 \mathrm{ng} / \mathrm{mL}$ one week later.

\section{Discussion}

To date, there are no reports of sirolimus interacting with nefazodone. Nefazodone inhibits the cytochrome P450 3A4 enzyme system; which can result in nefazodone increasing blood levels of medication that are metabolized by the cytochrome P450 3A4 enzyme system. ${ }^{1-3}$ Transplant medications metabolized by the cytochrome P450 3A4 enzyme system are: Tacrolimus, cyclosporine, and sirolimus. This can result in supratherapeutic or subtherapeutic transplant drug levels that may result in immunosuppression toxicity or transplant organ rejection when nefazodone is started or discontinued. This case highlights the importance of monitoring immunosuppression drug levels since the care of transplant patients requires the treatment with many medications that may frequently interact. It is also equally important to educate our patients to inform their transplant staff about any medications that are started or discontinued from any health care provider to prevent drug toxicity or organ rejection.

Our case is unique since the patient was on nefazodone pre-transplant and the drug interaction was not suspected since her cyclosporine dose was already frequently adjusted the first few weeks after transplant. In addition, the patient was later switched from cyclosporine to sirolimus and her sirolimus dose was adjusted based on sirolimus trough levels. The interaction was later discovered after the patient's sirolimus level was undetectable and the patient admitted her nefazodone was discontinued. This patient was several years post-transplant and demonstrated therapeutic stable sirolimus blood levels; therefore, her sirolimus levels were not monitored as often. Fortunately our patient did not have rejection with an undetectable sirolimus drug level. 
In conclusion, nefazodone may increase blood levels of medications that are metabolized by the cytochrome P450 3A4 enzyme system. It is important to closely monitor sirolimus blood levels when a drug, such as nefazodone, that may potentially interact is initiated, discontinued, or its dose is adjusted.

\section{Declaration of interest}

No financial support declared. All work has been done independently at Loyola University Medical Center; however, Laura Michalski currently works for Pfizer Inc.

\section{References}

1. Wright DH, Lake KD, Bruhn PS, Emery RW. Nefazodone and cyclosporine drug-drug interaction. J Heart Lung Transplant 1999; 18: 913-915.

2. Campo JV, Smith C, Perel JM. Tacrolimus toxic reaction associated with the use of nefazodone: Paroxetine as an alternative agent. Arch Gen Psychiatry 1998; 55: 1050-1052.

3. Sadaba B, Campanero MA, Quetglas EQ, Azanza JR. Clinical relevance of sirolimus drug interactions in transplant patients. Transplant Proc 2004;36: 3226-3228.

Author for correspondence:

Laura S. Michalski, Pharm.D., BCPS

25 Avenue at Port Imperial, Apt \#1120

West New York, NJ 07093

USA

Tel.: (201) 255-0905 and (312) 953-6125

Fax: (201) 210-8725

Email: lauramichalski@yahoo.com laura.michalski@pfizer.com 